\title{
Multilevel Small Area Estimation of Prostate-Specific Antigen Screening Test in the United States by Age Group: 2018 Behavioral Risk Factor Surveillance System
}

\author{
Zahava Berkowitz, MSPH, MSc, Xingyou Zhang, PhD, Thomas B. Richards, MD, \\ Susan A. Sabatino, MD, MPH, Lucy A. Peipins, PhD, and Judith Lee Smith, PhD
}

Background: In 2018, the US Preventive Services Task Force (USPSTF) recommended prostate cancer screening for men aged 55 to 69 years who express a preference for being screened after being informed about and understanding prostate-specific antigen (PSA) test benefits and risks. USPSTF recommended against screening men aged $\geq 70$ years. We aim to generate county-level prevalence estimates, masked by national and state estimates, to identify counties with high PSA screening prevalence.

Methods: We fitted multilevel logistic regression mixed models for 4 age groups $(\geq 40,40$ to 54,55 to $69, \geq 70$ years), using data from the 2018 Behavioral Risk Factor Surveillance System (BRFSS) (n = 116,654 ) and other sources. We evaluated consistency between our model-based state and BRFSS direct state estimates with Spearman and Pearson correlation coefficients.

Results: PSA screening prevalence increased with increasing age groups: $7.7 \%$ for men aged 40 to 54 years, $27.2 \%$ for men aged 55 to 69 years, and $33.7 \%$ among men age $\geq 70$ years, and was largely clustered in the South and Appalachia. Many county estimates among men aged $\geq 70$ years exceeded $40 \%$, especially in the South. Correlation coefficients were 0.94 for men aged $\geq 40$, and $\geq 0.85$ for men aged 40 to 54 years, 55 to 69 years, and $\geq 70$ years.

Conclusions: PSA screening was highest among men $\geq 70$ years, for whom it is not recommended, and in the South among all age groups. Screening varied substantially within states.

Impact: In 2018, on average, more than 1 in 4 men aged 55 to 69 years and 1 in 3 men aged $\geq 70$ years underwent PSA screening in the prior year, suggesting potential overuse among some men. (J Am Board Fam Med 2021;34:634-647.)

Keywords: Behavioral Risk Factor Surveillance System, County-Level Estimates, Early Detection of Cancer, Internal Consistency, Logistic Models, Multilevel Small Area Estimation, Prostate Cancer, Prostate-Specific Antigen, PSA, PSA Screening Prevalence

\section{Introduction}

In 2008, the US Preventive Services Task Force (USPSTF) recommended against prostate-specific

This article was externally peer reviewed.

Submitted 25 September 2020; revised 17 December 2020; accepted 11 January 2021.

From the National Center for Chronic Disease Prevention and Health Promotion, Centers for Disease Control and Prevention, Chamblee, GA (ZB, TBR, SAS, LAP, JLS); US Bureau of Labor Statistics, Washington, DC (XZ).

Funding: None.

Conflict of interest: The authors declare no potential conflicts of interest.

Note: This work was conducted in a government institution. No funds or grants were involved.

Disclaimer: The findings and conclusions in this report are those of the authors and do not necessarily represent the official position of the Centers for Disease Control and Prevention or the U.S. Bureau of Labor Statistics. antigen (PSA) screening test for prostate cancer for men aged 75 years or older, ${ }^{1}$ and in 2012 , the USPSTF recommended against PSA screening for men of all ages. ${ }^{2}$ In 2018, the USPSTF recommended that men should be informed about and understand the benefits and harms of screening and express a preference to be screened before the test is offered. ${ }^{3,4}$ This current recommendation is limited to men aged 55 to 69 years, for whom the net

Corresponding author: Zahava Berkowitz, MSPH, MSc, Epidemiology and Applied Research Branch, Division of Cancer Prevention and Control, National Center for Chronic Disease Prevention and Health Promotion, Centers for Disease Control and Prevention (CDC), 4770 Buford Highway, NE, Mailstop S107-4, Chamblee, GA, 30341, Phone: 770-488-4881 (E-mail: zab3@cdc.gov). 
benefits might be small (Grade $\mathrm{C}$ recommendation, selective offering). For men aged $\geq 70$ years, the USPSTF recommended against PSA screening (Grade D, discourage use), stating that the potential benefits do not outweigh the harms. ${ }^{4}$ Potential harms include false positives, overdiagnosis and overtreatment, and treatment complications, such as loss of normal urinary, bowel, and sexual functions. ${ }^{3}$ The USPSTF was not able to provide specific recommendations for men aged $<55$ years, for men with family history, or African-American men, who have increased risk of prostate cancer mortality. ${ }^{5,6}$ Although screening might offer potential benefits to some men among the youngest and oldest age groups, screening might also expose these men to adverse effects. ${ }^{4}$ PSA screening has been associated with disproportionate cost among men aged 70 years or older. ${ }^{7}$

Currently few publications review geospatial variations in PSA screening in the United States. Although recent studies identified predictors associated with PSA screening, few have described variations among states or US Census regions. ${ }^{8-12}$ National, regional and state-level estimates can mask the variations in PSA screening within states. ${ }^{13}$ Previous analyses of breast and colorectal cancer screening ${ }^{14,15}$ found large variations between and within states with striking geographical distributions. To improve knowledge of PSA screening in smaller areas, we performed a countylevel analysis to describe the prevalence of PSA screening by county, and by age groups for whom USPSTF conclusions varied. Small area estimates (SAE) can help identify areas of frequent screening, especially among men aged 70 or older for some of whom screening could reflect overuse. Estimates may also inform public health research, programmatic, and communication efforts.

\section{Materials and Methods}

We used data from the 2018 Behavioral Risk Factor Surveillance System (BRFSS) about PSA screening among men aged 40 years or older. ${ }^{16}$ The BRFSS is a state-based cross-sectional, health-related telephone survey collecting data from noninstitutionalized US adults aged 18 years or older. The Centers for Disease Control and Prevention (CDC) administers the BRFSS annually in collaboration with state health departments and the District of Columbia. The survey's combined landline and cell phone weighted response rates in 2018 ranged from $67.2 \%$ in South Dakota to $38.8 \%$ in California, with a median rate of $49.9 \%$. Detailed information about the survey is presented on the BRFSS website. $^{16}$

Men aged 40 years or older were asked "Have you ever had a PSA test?" Those who answered "No" were assigned as never having had the test. Men who answered "Yes" were asked, "How long has it been since you had your last PSA test?" Men who reported having had the test within the past year were further asked "What was the main reason you had this PSA test?" Answers included the following choices: "as part of a routine examination"; "because of a prostate problem," "because of a family history of prostate cancer," "because you were told you had prostate cancer," or "some other reason." We examined the outcome of having had PSA test "within the past year (any time less than 12 months)" and included only men who were tested as part of a routine examination to study screening prevalence and be consistent with previous studies. ${ }^{8,12,17,18}$ Men who were tested within 1 year for other reasons were excluded from the analysis. We also excluded men who responded "do not know/not sure" $(6.8 \%)$ and those who refused to answer (1\%).

\section{Statistical Analysis}

We used individual-level data with county-of-residence from the 2018 BRFSS restricted data set after adding state and county information to each BRFSS record. Of 130,547 men aged 40 years or older who responded to the question about whether they had ever had a PSA test, a sample of 116,654 men (representing nearly 60.3 million men) was used for our analysis after exclusions. We linked these data to the 2018 American Community Survey 5-year county-level poverty estimates, ${ }^{19}$ received from the US Census, to fit multilevel logistic regression models with both fixed and random effects. ${ }^{20}$ Fixed effects included 9 age groups ( 40 to 44,45 to 49,50 to 54,55 to 59,60 to 64,65 to 69,70 to 74,75 to 79 , and $\geq 80$ years), 7 racial and ethnic groups, (non-Hispanic $[\mathrm{NH}]$ white, $\mathrm{NH}$ black, NH American Indian/Alaska Native [(AIAN)], NH Asian, NH Pacific Islander, 2 or more races, and Hispanic), and county-level poverty $(<150 \%$ of the federal poverty rate). We excluded BRFSS respondents coded as "other race" 
from our analysis since this category was not part of the US Census data. Random effects were stateand county levels. Our multilevel logistic regression models were fitted with unweighted data using the GLIMMIX procedure, SAS version 9.4 (SAS Institute, Inc., Cary, NC). This approach was justified by 2 validation studies showing the benefits to the estimates' accuracy compared with those of weighted data. ${ }^{21,22}$ Some counties' random effects were missing because they did not have any BRFSS respondents available for analysis. To complete the list of random effects for all counties, we generated county-level random effects for these counties with missing data by averaging the neighboring counties' random effects. Further details about the reasons for our choice of the smoothing method are described previously. ${ }^{23-24} \mathrm{We}$ post-stratified the predicted probability of having a PSA screening test by 197,946 ( 9 age groups $\mathrm{x} 7$ race/ethnicity groups x 3142 counties) specific geodemographic groups with US Census estimated county population counts $^{25}$ and estimated their corresponding standard errors using a Monte Carlo simulation method. The poststratification process adjusts the estimates using a weighted average of estimates from all possible geodemographic combinations ("197,946 cells”). We aggregated these specific geodemographic group prevalence estimates of having had a PSA screening test to generate county-level prevalence estimates and their standard errors for all men aged 40 or older, and for men in each of 3 age groups, including 2 age groups for whom the USPSTF issued recommendations (40 to 54,55 to $69, \geq 70$ years). Further details about our methodology to generate county-level estimates and aggregate them to state and national-level estimates are described in prior studies. ${ }^{14,20}$

We did not present detailed information for age-group 40 to 54 years, for whom no recommendation was made.

Because BRFSS is a state-based surveillance system, we compared our model-based state-specific estimates with their corresponding BRFSS direct (weighted) state estimates and evaluated their internal consistency using the Spearman and Pearson correlation coefficients.

To help the reader identify patterns of PSA screening uptake on a national level, we presented a descriptive table of the unweighted and weighted percentages of PSA screening within 1 year by age, race, and ethnicity groups using the BRFSS 2018 data. The unweighted and weighted percentages reflect findings both in the sample and the study population respectively.

\section{Results}

Our descriptive analysis shows that PSA screening increased with increasing age groups but decreased among men aged 80 years or older. Nationally, men aged 70 to 79 years had the highest weighted percentage of PSA screening at $37.5 \%$. Non-Hispanic White men $(22.5 \%)$, followed by Non-Hispanic Black men (18.4\%), had the highest PSA screening uptakes while Hispanic and non-Hispanic Pacific Islanders had the lowest, at $<12.0 \%$ (Appendix Table 1).

Our county-level findings show that, after poststratification, our simulation program generated estimates for all 3142 counties in the US. The BRFSS data analysis, using the GLIMMIX procedure, however, had 140 counties where random effects were missing. Most of these counties were in rural areas.

At a national level, the prevalence (mean percent) estimate generated by the model-based SAE for men aged 40 years or older who had a PSA screening test was $20.6 \%$ (95\% Confidence Interval [CI], 20.2\%-21.0\%; Table 1). This estimate was slightly higher than the direct 2018 BRFSS prevalence estimate: 19.8\%, (95\% CI, 19.3\%-20.2\%), which represented 11,913,307 men. The national SAE county mean estimate was $21.9 \%$, and the estimates varied from $7.9 \%$ to $38.1 \%$. National prevalence increased with increasing age-group (7.7\%, $27.2 \%$, and $33.7 \%$ for men aged 40 to 54,55 to 69 , $\geq 70$ years, respectively) and were almost the same as the direct BRFSS estimates. Mean county prevalence also increased in higher age groups. The ranges in county prevalence for the 3 age groups were $8.3 \%$ for ages 40 to 54 years, $30.0 \%$ for ages 55 to 69 years, and $37.1 \%$ for ages $\geq 70$ years.

At the state level, Spearman and Pearson correlation coefficients between the SAE model statelevel estimates and the BRFSS direct state estimates were 0.94 for all men aged $\geq 40$ years, 0.94 and 0.89 for ages 40 to 54 years, 0.89 and 0.92 for ages 55 to 69 years, and 0.86 and 0.85 among men aged $\geq 70$ years, respectively (Table 2 ). Overall modelbased and BRFSS mean and median states' estimates were similar. 
Table 1. National Estimates From the 2018 Behavioral Risk Factor Surveillance System (BRFSS), and ModelBased PSA Screening Summary Estimates for the Total Population and 3142 Counties, by Age Group ${ }^{*} \dagger$

\begin{tabular}{|c|c|c|c|c|c|c|c|c|}
\hline \multirow[b]{2}{*}{ Age Group, years } & \multirow{2}{*}{$\frac{\text { BRFSS } 2018}{\text { Mean }(95 \% \text { CI) }}$} & \multicolumn{6}{|c|}{ Model-based national and county summary statistics } & \multirow[b]{2}{*}{ Overall Range } \\
\hline & & Mean $(95 \% \mathrm{CI})$ & Min & Q1 & Median & Q3 & Max & \\
\hline \multicolumn{9}{|l|}{$\geq 40$} \\
\hline US & $19.77(19.31-20.24)$ & $20.59(20.18-21.00)$ & & & & & & \\
\hline Counties & & 21.93 & 7.87 & 20.00 & 22.27 & 24.07 & 38.14 & 30.27 \\
\hline \multicolumn{9}{|l|}{40 to 54} \\
\hline US & $7.85(7.38-8.36)$ & $7.67(7.43-7.92)$ & & & & & & \\
\hline Counties & & 7.82 & 4.33 & 7.26 & 7.8 & 8.32 & 12.62 & 8.28 \\
\hline \multicolumn{9}{|l|}{55 to 69} \\
\hline US & $26.72(25.89-27.56)$ & $27.23(26.50-27.96)$ & & & & & & \\
\hline Counties & & 27.75 & 10.52 & 25.60 & 28.05 & 30.31 & 40.51 & 29.99 \\
\hline \multicolumn{9}{|l|}{$\geq 70$} \\
\hline US & $33.39(32.16-34.65)$ & $33.67(32.64-34.67)$ & & & & & & \\
\hline Counties & & 34.22 & 15.60 & 30.82 & 34.23 & 37.61 & 52.66 & 37.06 \\
\hline
\end{tabular}

PSA, Prostate-specific antigen; Min, Minimum; Q1, $25^{\text {th }}$ percentile; Q3, $75^{\text {th }}$ percentile; Max, Maximum; CI, Confidence interval. *2018 BRFSS sample size for age $\geq 40$ is 116,654 . BRFSS percentages are weighted to the study population.

${ }^{\dagger}$ Estimates are presented as percentages (\%). Model-based results are based on data from the 2018 BRFSS, US Census 2018 American Community Survey 5 -year county-level poverty estimates, and the US Census estimated county population counts.

Geographic patterns of PSA screening were similar overall and among men aged 55 to 69 and $\geq 70$ years (Appendix Figure 1a-1c): the largest cluster of states with high prevalence was in the South, Appalachian states, such as Ohio, West Virginia, and Tennessee, and part of the Midwest. Among men aged $\geq 40$ years, estimated state prevalence ranged from $14.4 \%$ in New Mexico to $27.0 \%$ in West Virginia (Table 3). The range of county estimates within a state varied from 1.9 percentage

Table 2. Spearman and Pearson Correlation Coefficients Between Model-Based PSA Screening State-Level Estimates and BRFSS 2018 Direct State Estimates, by Age Group* $*$

\begin{tabular}{|c|c|c|c|c|c|c|c|}
\hline \multirow[b]{2}{*}{ Age Group, years } & \multirow[b]{2}{*}{ No. of States } & \multicolumn{2}{|c|}{ Correlation $^{\ddagger}$} & \multirow[b]{2}{*}{$\operatorname{Min}(\%)$} & \multirow[b]{2}{*}{ Mean (\%) } & \multirow[b]{2}{*}{ Median (\%) } & \multirow[b]{2}{*}{$\operatorname{Max}(\%)$} \\
\hline & & Spearman $^{\S}$ & Pearson" & & & & \\
\hline$\geq 40$ & 51 & 0.94 & 0.94 & & & & \\
\hline Model-based & & & & 14.36 & 20.71 & 20.94 & 27.00 \\
\hline BRFSS & & & & 12.18 & 19.54 & 19.88 & 27.52 \\
\hline 40 to 54 & 51 & 0.94 & 0.89 & & & & \\
\hline Model-based & & & & 4.52 & 7.68 & 7.74 & 10.31 \\
\hline BRFSS & & & & 2.65 & 7.73 & 7.39 & 13.77 \\
\hline 55 to 69 & 51 & 0.89 & 0.92 & & & & \\
\hline Model-based & & & & 17.88 & 27.13 & 27.58 & 32.84 \\
\hline BRFSS & & & & 15.26 & 26.07 & 25.77 & 34.56 \\
\hline$\geq 70$ & 51 & 0.86 & 0.85 & & & & \\
\hline Model-based & & & & 24.40 & 33.62 & 33.10 & 44.18 \\
\hline BRFSS & & & & 23.45 & 33.46 & 33.51 & 41.06 \\
\hline
\end{tabular}

PSA, prostate-specific antigen; BRFSS, Behavioral Risk Factor Surveillance System; Min, Minimum; Max, Maximum.

*BRFSS 2018 sample size for age $\geq 40$ is 116,654. BRFSS percentages used for comparisons with the Model-based are weighted to the study population. The total number of counties in the model-based is 3,142 .

${ }^{\dagger}$ Model-based results are based on data from 2018 BRFSS, US Census 2018 American Community Survey 5-year county-level poverty estimates, and the US Census estimated county population counts.

${ }^{\ddagger}$ Correlation coefficients between model-based state-level estimates and 2018 BRFSS direct state estimates.

${ }^{\S}$ Spearman correlation coefficient; "Pearson correlation coefficient. 
Table 3. Model-Based SAE State Prevalence Estimate, and County Statistics Summarized by State for PSA Screening Among Men Aged $\geq 40$ Years, for 50 States, the District of Columbia, and 3142 Counties, 2018

\begin{tabular}{|c|c|c|c|c|c|c|c|c|}
\hline \multirow[b]{2}{*}{ State } & \multirow[b]{2}{*}{ State Mean* } & \multicolumn{7}{|c|}{ County Summary Statistic* } \\
\hline & & Min & Q1 & Mean & Median & Q3 & Max & Range $^{\dagger}$ \\
\hline Alabama & 24.98 & 20.03 & 23.13 & 24.45 & 24.53 & 25.50 & 30.24 & 10.21 \\
\hline Alaska & 19.14 & 7.87 & 13.56 & 16.57 & 17.82 & 19.40 & 22.39 & 14.52 \\
\hline Arizona & 21.76 & 10.97 & 15.92 & 19.15 & 19.17 & 21.81 & 26.71 & 15.74 \\
\hline Arkansas & 23.12 & 18.38 & 21.47 & 27.67 & 22.40 & 23.96 & 27.33 & 8.95 \\
\hline California & 15.85 & 11.65 & 15.01 & 16.94 & 16.38 & 18.84 & 23.22 & 11.57 \\
\hline Colorado & 17.36 & 11.56 & 16.93 & 18.73 & 18.86 & 20.33 & 24.36 & 12.80 \\
\hline Connecticut & 21.69 & 18.25 & 20.68 & 21.62 & 22.25 & 22.81 & 23.23 & 4.97 \\
\hline Delaware & 24.43 & 22.00 & 22.00 & 25.10 & 23.75 & 29.54 & 29.54 & 7.54 \\
\hline District of Columbia & 17.76 & & & 17.76 & & & & \\
\hline Florida & 25.61 & 19.21 & 22.58 & 25.38 & 24.87 & 27.68 & 38.14 & 18.94 \\
\hline Georgia & 24.14 & 17.78 & 23.22 & 24.47 & 24.23 & 25.63 & 32.01 & 14.23 \\
\hline Hawaii & 15.64 & 14.98 & 15.46 & 15.83 & 15.73 & 16.10 & 16.88 & 1.90 \\
\hline Idaho & 20.17 & 15.42 & 18.74 & 20.55 & 20.65 & 22.16 & 24.66 & 9.24 \\
\hline Illinois & 19.44 & 16.30 & 21.14 & 22.11 & 22.09 & 23.15 & 25.88 & 9.57 \\
\hline Indiana & 19.43 & 16.71 & 18.94 & 19.78 & 19.76 & 20.53 & 22.79 & 6.08 \\
\hline Iowa & 21.22 & 16.63 & 21.23 & 22.22 & 22.32 & 23.14 & 27.31 & 10.68 \\
\hline Kansas & 22.55 & 14.46 & 23.13 & 23.99 & 24.43 & 25.47 & 29.06 & 14.60 \\
\hline Kentucky & 21.86 & 16.74 & 20.84 & 21.98 & 22.00 & 23.11 & 27.60 & 10.86 \\
\hline Louisiana & 23.81 & 17.01 & 21.94 & 23.02 & 22.92 & 24.14 & 27.21 & 10.20 \\
\hline Maine & 15.84 & 13.71 & 14.49 & 15.93 & 15.74 & 16.81 & 19.21 & 5.49 \\
\hline Maryland & 19.55 & 16.43 & 18.21 & 20.57 & 19.84 & 22.96 & 25.74 & 9.30 \\
\hline Massachusetts & 18.39 & 16.11 & 17.78 & 19.10 & 18.37 & 19.68 & 25.69 & 9.58 \\
\hline Michigan & 20.27 & 17.20 & 19.94 & 21.31 & 21.16 & 22.44 & 26.51 & 9.31 \\
\hline Minnesota & 17.69 & 14.67 & 18.09 & 19.14 & 19.26 & 19.99 & 23.54 & 8.87 \\
\hline Mississippi & 23.53 & 17.31 & 22.01 & 23.02 & 23.16 & 24.53 & 27.75 & 10.43 \\
\hline Missouri & 23.93 & 19.26 & 23.00 & 24.00 & 24.07 & 25.12 & 29.74 & 10.47 \\
\hline Montana & 23.87 & 15.48 & 23.02 & 24.56 & 25.52 & 26.73 & 29.16 & 13.67 \\
\hline Nebraska & 20.12 & 16.09 & 21.26 & 22.64 & 23.08 & 24.00 & 28.83 & 12.74 \\
\hline Nevada & 17.21 & 15.81 & 17.20 & 19.02 & 18.58 & 19.52 & 25.94 & 10.13 \\
\hline New Hampshire & 19.29 & 15.38 & 17.04 & 19.02 & 19.59 & 20.02 & 23.31 & 7.92 \\
\hline New Jersey & 24.20 & 18.95 & 23.24 & 24.63 & 25.49 & 26.80 & 29.03 & 10.08 \\
\hline New Mexico & 14.36 & 8.37 & 13.75 & 14.98 & 14.69 & 16.33 & 20.44 & 12.07 \\
\hline New York & 20.68 & 14.45 & 19.03 & 20.43 & 20.68 & 22.03 & 28.58 & 14.13 \\
\hline North Carolina & 23.66 & 17.19 & 22.67 & 24.17 & 23.94 & 25.29 & 32.34 & 15.14 \\
\hline North Dakota & 21.37 & 10.70 & 21.57 & 22.97 & 23.79 & 24.86 & 27.87 & 17.17 \\
\hline Ohio & 21.97 & 17.09 & 21.11 & 22.28 & 21.92 & 23.50 & 27.88 & 10.79 \\
\hline Oklahoma & 23.32 & 17.24 & 22.56 & 23.33 & 23.22 & 24.36 & 27.18 & 9.94 \\
\hline Oregon & 15.97 & 13.27 & 16.23 & 17.09 & 17.22 & 18.46 & 20.15 & 6.88 \\
\hline Pennsylvania & 21.90 & 18.76 & 21.30 & 22.32 & 22.38 & 23.10 & 25.86 & 7.10 \\
\hline Rhode Island & 20.60 & 18.53 & 20.56 & 22.91 & 23.25 & 25.37 & 26.82 & 8.29 \\
\hline South Carolina & 26.14 & 20.44 & 23.16 & 25.14 & 24.95 & 26.17 & 34.97 & 14.53 \\
\hline South Dakota & 21.73 & 8.57 & 19.94 & 21.37 & 22.70 & 24.16 & 26.06 & 17.49 \\
\hline Tennessee & 23.25 & 18.99 & 22.99 & 23.88 & 23.90 & 24.97 & 30.26 & 11.23 \\
\hline Texas & 18.59 & 11.22 & 18.22 & 20.30 & 20.60 & 22.64 & 29.21 & 17.99 \\
\hline Utah & 16.52 & 12.43 & 16.95 & 18.19 & 18.61 & 20.30 & 23.07 & 10.64 \\
\hline Vermont & 15.02 & 12.62 & 13.65 & 15.15 & 15.34 & 16.08 & 19.14 & 6.52 \\
\hline Virginia & 20.94 & 15.11 & 20.41 & 22.06 & 22.13 & 23.67 & 27.82 & 12.70 \\
\hline
\end{tabular}




\begin{tabular}{|c|c|c|c|c|c|c|c|c|}
\hline \multirow[b]{2}{*}{ State } & \multirow[b]{2}{*}{ State Mean* } & \multicolumn{7}{|c|}{ County Summary Statistic* } \\
\hline & & Min & Q1 & Mean & Median & Q3 & Max & Range $^{\dagger}$ \\
\hline Washington & 15.44 & 13.01 & 15.52 & 17.45 & 17.13 & 19.92 & 22.68 & 9.67 \\
\hline West Virginia & 27.00 & 22.52 & 25.56 & 26.79 & 26.77 & 27.96 & 31.79 & 9.38 \\
\hline Wisconsin & 19.56 & 12.96 & 19.65 & 20.49 & 20.42 & 21.46 & 25.03 & 12.07 \\
\hline Wyoming & 24.57 & 20.86 & 22.96 & 24.74 & 24.56 & 26.83 & 29.82 & 8.96 \\
\hline
\end{tabular}

SAE, small area estimation; PSA, prostate-specific antigen; Min, Minimum; Max, Maximum; Q1, 25 ${ }^{\text {th }}$ percentile; Q3, $75^{\text {th }}$ percentile; BRFSS, Behavioral Risk Factor Surveillance System.

*State prevalence is presented as means and estimates are presented as percentages (\%). Model-based results are based on data from the 2018 BRFSS, US Census 2018 American Community Survey 5-year county-level poverty estimates, and the US Census estimated county population counts.

${ }^{\dagger}$ Range means the difference between the minimum and maximum estimated percentages.

points in Hawaii to 18.9 percentage points in Florida (Table 3).

At both state and county levels, PSA screening prevalence was higher for men aged $\geq 70$ years compared with men aged 55 to 69 years (Table 4). State prevalence (mean percent) of PSA screening among men aged 55 to 69 years, for whom the USPSTF recommendations emphasized informed decision-making for screening, varied from $17.9 \%$ in New Mexico to $32.8 \%$ in Delaware (Table 4). County prevalence among the states ranged from a minimum of $10.5 \%$ in Alaska to a maximum of $\geq 40.0 \%$ in Alabama, Arkansas, and Florida, with 9 states having a median county prevalence of $\geq 30.0 \%$. The states' overall county ranges (minimum to maximum) for this agegroup varied from $4.7 \%$ in Hawaii to $25.1 \%$ in South Dakota. States having their $25^{\text {th }}$ percentile of county prevalence at $20.6 \%$ (the model's national county mean, Table 1) or lower, included Hawaii, Alaska, Washington, Oregon, California, New Mexico, Vermont, New Hampshire, and Maine.

Similar patterns of variation in PSA screening in state and county prevalence estimates were observed among men aged $\geq 70$ years (Table 4 ). For these men, 20 states had a prevalence $\geq 35.0 \%$ of which the majority were in the South. Some of these states had their $75^{\text {th }}$ percentile of county prevalence at $40.0 \%$ or more, including Delaware, West Virginia, North Carolina, South Carolina, Florida, Georgia, Alabama, Mississippi, Oklahoma, and $W_{y o m i n g}$. The overall county ranges for men aged $\geq 70$ years varied from $6.8 \%$ in Delaware to $25.4 \%$ in South Dakota.

\section{Discussion}

In 2018, we estimated that, on average, 1 in 5 men aged 40 years or older received recent PSA screening. PSA screening increased with age, with the highest prevalence occurring in men aged 70 years or older, similar to previous findings albeit with somewhat different age groups. ${ }^{8,9,17,26,27}$ The USPSTF recommendation against screening is longest standing for the oldest men, dating back to 2008 for men aged 75 years or older. ${ }^{1}$ Our estimates show that, on average, 1 in 3 men aged 70 years or older had PSA screening in the past year. Using the 2018 BRFSS data, we estimated that more than 3.76 million men aged 70 years or older had routine screening during the past year. During 2012 to 2017, major organizations varied in their recommendations on PSA screening. The USPSTF did not recommend PSA screening, but Medicare continued to reimburse annual PSA screening tests. ${ }^{28}$ In 2018, the USPSTF recommended shared decision-making before the initiation of PSA screening. The emphasis on shared decision-making is consistent with current recommendations by the American Cancer Society (ACS) ${ }^{29}$ and the American Urologic Association (AUA). ${ }^{30}$ We cannot draw conclusions about the relationship between the 2018 USPSTF recommendations and the study results because the implementation of recommendations to clinical practice may require several years, and some providers may follow an older recommendation from other groups.

Our 3 county-level maps revealed a similarity among men aged 55 to 69 and $\geq 70$ years in areas of high PSA screening prevalence in the United States. Among men aged 40 and over, the largest 
number of counties with the highest prevalence was concentrated in the South, in parts of the Appalachian regions, New Jersey, Kansas, Missouri, and Wyoming. Multiple factors may contribute to the high screening in these areas, such as differences in populations by race, the proportion of older men, or geographic differences in provider intensity of screening practice patterns. ${ }^{31}$ For example, the average percentage of adults aged 65 years or older in the Appalachian region is higher than the national average $\left(17.6 \%\right.$ vs $15.2 \%$, respectively). ${ }^{32}$ It is unknown how Medicare annual reimbursement $^{28}$ might have contributed to the observed screening patterns. Our findings that, nationally, men aged 70 to 79 years had the highest prevalence of screening, and men aged 80 years and older had a prevalence greater than $23 \%$ may suggest reimbursement's influence on screening. Geographic analyses revealed that screening prevalence was highest in the South regardless of age-group. The wide difference in the prevalence of screening among other states in the United States might also indicate the role providers' practice plays in the high prevalence of screening. Differences in provider types across geographic areas and urban and rural communities, ${ }^{33}$ in organizations that most frequently influence providers' practices, ${ }^{34,35}$ and in patients' preferences could contribute to varying screening use.

Prostate cancer mortality has declined over time. ${ }^{36}$ The prevalence of PSA screening has also declined after the 2012 USPSTF recommendations against routine PSA screening in all men. Despite longer standing recommendations against routine screening for older men, similar to previous findings, ${ }^{8}$ we found screening prevalence has continued to be higher in men aged 70 or older than among younger men. State-level prevalence was as high as $44.2 \%$ for men age 70 and older, and county-level prevalence in the $75^{\text {th }}$ percentile reached $48.6 \%$, compared with $32.8 \%$ and $35.9 \%$ in men aged 55 to 69 years, respectively. States' and counties' overall prevalence ranges were $19.8 \%$ and $37 \%$ respectively, indicating considerable variation in the screening of older men across communities. Higher screening use among men aged 70 years or older may reflect, in part, physicians' concerns that older men are more likely to be diagnosed with and die from prostate cancer than are younger men, ${ }^{37-39}$ and changes in recommendations may not alter attitudes toward PSA screening practices for some providers. ${ }^{40}$ Higher screening prevalence among older men may also reflect men's preferences. In a web-based survey of men aged 40 to 74 years without prior prostate cancer, most men reported not intending to follow the 2012 USPSTF recommendation. Men aged $\geq 60$ years were somewhat more likely to report this, although the finding for older men did not persist in the adjusted analysis. ${ }^{41}$ This same study reported that worry about developing prostate cancer was associated with the intention to not follow the 2012 recommendation. A different study, aimed at identifying sources of prostate cancer decisional regret with a focus on racial disparities, found that despite an increased risk of prostate cancer among African American men, they had higher medical mistrust and concerns about masculinity than non-African American men, which the authors suggested might have contributed to a higher level of decisional regret. ${ }^{42}$

In our study, the PSA screening prevalence among men $\geq 70$ years suggests potential overuse and deserves attention. The USPSTF, ACS, and AUA indicated that the length of time required to experience any potential prostate cancer mortality benefit is greater than 10 years. ${ }^{1,29,30}$ Because a 75 year-old man has an average life expectancy of about 10 years, many men aged 75 years or older would likely not experience a mortality benefit. ${ }^{43}$ Similarly, men younger than 75 years, who have chronic health conditions and a life expectancy of fewer than 10 years, are also unlikely to benefit from screening and treatment. ${ }^{1,29,30}$ All 3 organizations also raise concerns about potential harms of screening in this age-group, including overdiagnosis of low-risk cases that would not affect life expectancy and treatment-related harms. ${ }^{4}$ These organizations concluded that for men aged $\geq 70$ years, benefits would not outweigh potential harms and, therefore, have not recommended screening for this group.

The high PSA screening prevalence estimates in some states and counties among men 55 to 69 years suggest a need for a heightened provider and patient awareness about understanding the benefits and risks of screening, and patients' values and preferences of screening. Large variations in PSA screening among states and counties for men age 55 to 69 years were present. Nationally, screening prevalence was estimated to be $27 \%$ in this agegroup, with a range of state prevalence estimates of $15 \%$, and county prevalence estimates of $30 \%$. 


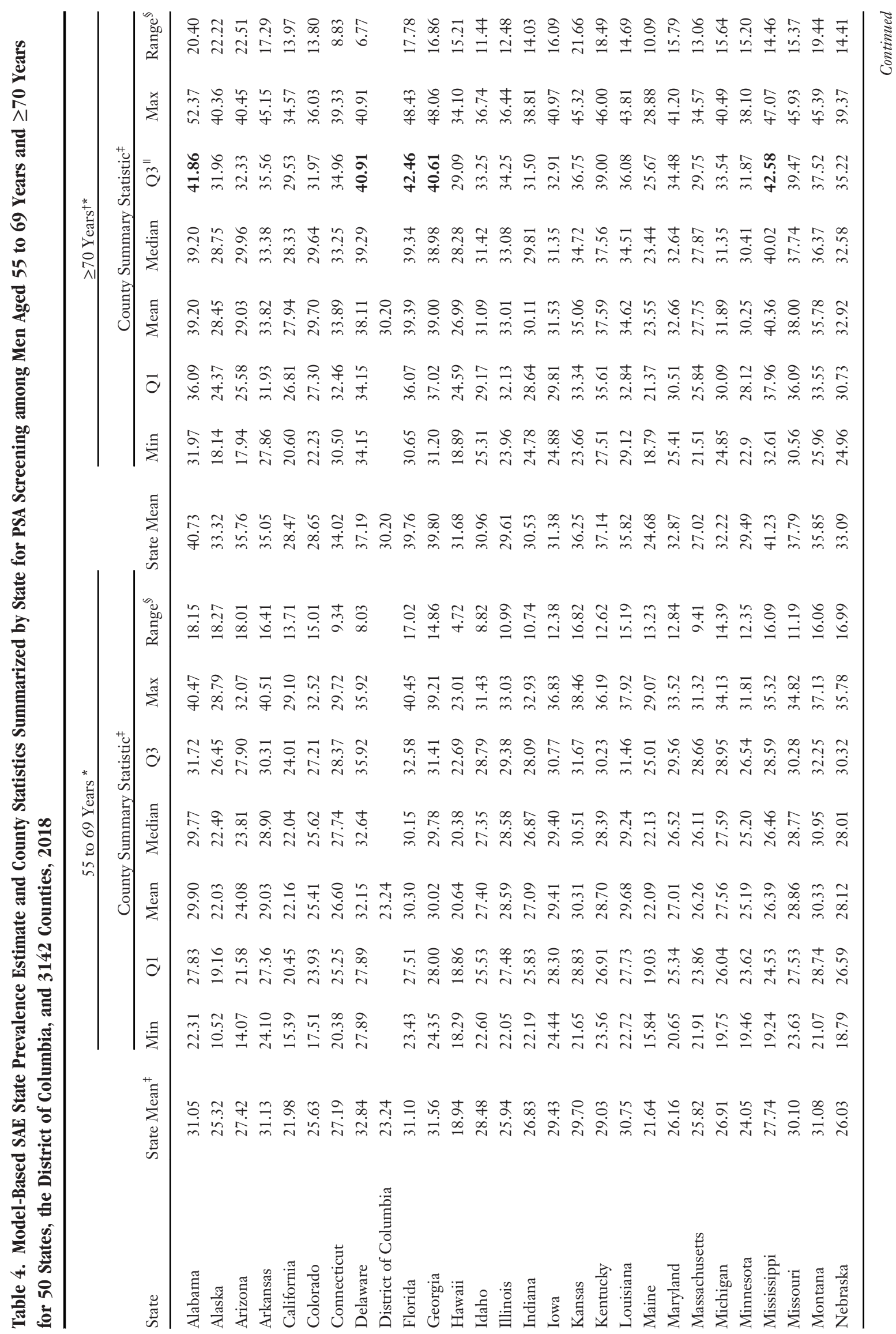




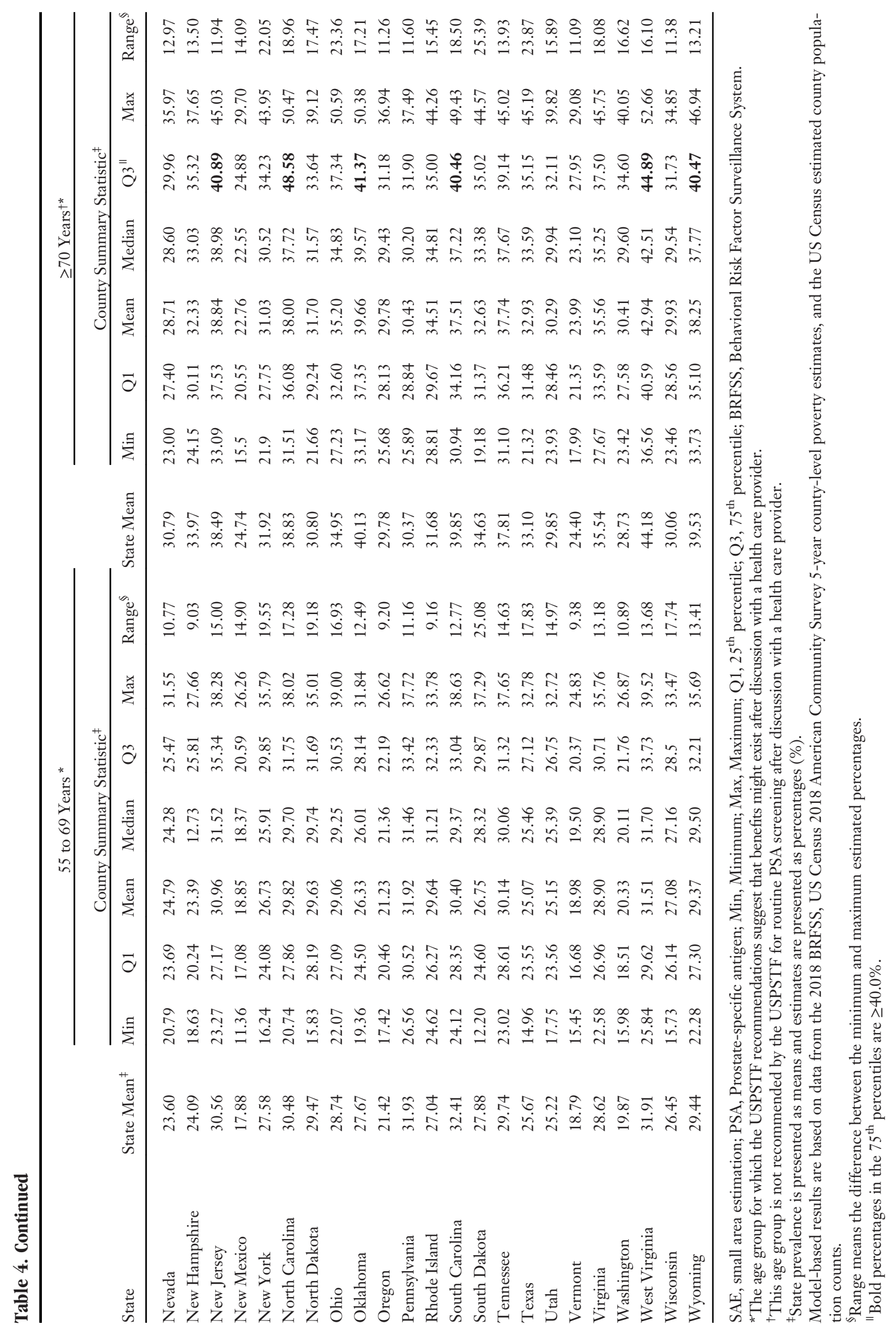


Because estimates are based on 2018 data about PSA screening in the prior year, the 2012 USPSTF recommendation against routine screening applied to this age-group as well. In 2018, USPSTF concluded that screening decisions should be based on men's expressed preferences after they are informed and understand potential benefits and harms. ${ }^{4}$ Thus, estimates provide a baseline for future monitoring of PSA screening after the 2018 USPSTF recommendation.

\section{Limitations and Strengths}

There are several limitations to our study. First, we used cross-sectional data, which does not determine cause and effect relationships between the outcomes and the covariates. Second, the PSA screening data are based on participant self-reports and were not validated with medical records information. Third, we do not know whether informed decision-making has affected screening because of insufficient data. Lastly, the US Census estimated county population count data did not include the category "Other race" as part of the race variable. Therefore, we excluded respondents in this race group from our BRFSS analysis. Nevertheless, our multilevel regression and poststratification approach has been previously validated internally and externally for county-level estimates. ${ }^{21,22}$ More research of spatial structure effects on SAE estimation is warranted to reduce bias and increase the precision of these estimates.

Despite these limitations, our study provided county-level estimates from the most recently available data for all the counties in the United States. Our models' estimates, when aggregated, were consistent with reliable direct BRFSS state estimates. A 2016 study comparing individuallevel estimates with area-level SAE estimators showed that individual-level, multilevel models consistently performed better for SAE estimation than area-level estimators. ${ }^{44}$

In conclusion, by using an individual-level multilevel estimation method with multiple data sources, we were able to generate estimates for all the counties in the United States, including those without or insufficient sample size for a stable analysis of BRFSS data. The respective national prevalence model-based estimates of the 4 age groups were very similar to the direct BRFSS estimates. We found large variations in PSA screening prevalence within many states. We observed an increased frequency of screening as age increased, and, inconsistent with all prostate cancer screening recommendations, men aged $\geq 70$ years had the highest screening prevalence. Our analysis identified areas in which potential overuse of PSA screening among older men may be prevalent. In addition, our analysis identified similar geographic patterns of PSA screening in men aged 55 years and older, raising questions about whether health care providers who are "PSA screeners" in older men may be more likely to screen younger men. Further research is warranted to understand the reasons for the screening prevalence we observed, as well as monitor screening use after the 2018 current recommendations. Interventions leading to informed decision-making among men about prostate cancer screening ${ }^{45}$ and more knowledge about clinicians' practices may help improve screening practices and reduce potential screening overuse in areas of high PSA uptake.

We thank Hua Lu for her support in getting the US Census and American Community Survey data.

To see this article online, please go to: http://jabfm.org/content/ 34/3/634.full.

\section{References}

1. US Preventive Services Task Force. Screening for prostate cancer: US Preventive Services Task Force recommendation statement. Ann Intern Med 2008;149:185-91.

2. Moyer VA. US Preventive Services Task Force. Screening for prostate cancer: US Preventive Services Task Force recommendation statement. Ann Intern Med 2012;157:120-34.

3. Fenton JJ, Weyrich MS, Durbin S, Liu Y, Bang H, Melnikow J. Prostate-specific antigen-based screening for prostate cancer. evidence report and systematic review for the US Preventive Services Task Force. JAMA 2018;319:1914-31.

4. US Preventive Services Task Force. Screening for Prostate Cancer. US Preventive Services Task Force recommendation statement. JAMA 2018;319:1901-13.

5. Howlader N, Noone AM, Krapcho M, et al. SEER Cancer Statistics Review, 1975-2016. Bethesda, MD: National Cancer Institute. Available from: https://seer.cancer.gov/csr/1975_2016/. Accessed December 15, 2020.

6. Tsodikov A, Gulati R, de Carvalho TM, et al. Is prostate cancer different in black men? Answers from 3 national history models. Cancer 2017;123: 2312-9.

7. Rao K, Liang S, Cardamone M, et al. Cost implications of PSA screening differ by age. BMC Urol 2018;18:38. 
8. Berkowitz Z, Li J, Richards TB, Marcus PM. Patterns of prostate-specific antigen test in the U.S., 2005-2015. Am J Prev Med 2017;53:909-13.

9. Hall IJ, Tangka FKL, Sabatino SA, Thompson BS, Graubard BI, Breen N. Patterns and trends in cancer screening in the United States. Prev Chronic Dis 2018;15:e97.

10. Negoita S, Feuer EJ, Mariotto A, et al. Annual report to the nation on the status of cancer, part ii: recent changes in prostate cancer trends and disease characteristics. Cancer 2018;124:2801-14..

11. DeRouen MC, Schupp CW, Koo J, et al. Impact of an individual and neighborhood factors on disparities in prostate cancer survival. Cancer Epidemiol 2018;53:1-11.

12. Vetterlein MW, Dalela D, Sammon JD, et al. State-by-state variations in prostate-specific antigen screening trends following the 2011 United States Preventive Services Task Force panel update. Urology 2018;112:56-65.

13. Jindal T, Kachroo N, Sammon J, et al. Racial differences in prostate-specific antigen-based prostate cancer screening: State-by-state and region-byregion analyses. Urol Oncol 2017;35:460.e9-460e20.

14. Berkowitz Z, Zhang X, Richards TB, et al,. Multilevel regression for small-area estimation of mammography use in the United States, 2014. Cancer Epidemiol Biomarkers Prev 2019;28:32-40.

15. Berkowitz Z, Zhang X, Richards TB, Nadel M, Peipins LA, Holt J. Multilevel small-area estimation of colorectal cancer screening in the United States. Cancer Epidemiol Biomarkers Prev 2018;27:245-53.

16. Office of Surveillance, Epidemiology and Laboratory Services, Centers for Disease Control and Prevention. Behavioral Risk Factor Surveillance System: 2014 Summary Data Quality Report. Atlanta, GA: Centers for Disease Control and Prevention; 2014. Available from: http://www.cdc. gov/brfss/annual_data/annual_2018.html. Accessed December 15, 2020.

17. Li J, Ding H, Richards TB, Martin I, Kobrin S, Marcus PM. Prostate-specific antigen screening initiation and shared decision-making: findings from the 2000 and 2015 National Health Interview Surveys. J Am Board Fam Med 2018;31:658-62.

18. Li J, Berkowitz Z, Richards TB, Richardson LC. Shared decision making in prostate-specific antigen screening with men older than 70. J Am Board Fam Med 2013;26:401-8.

19. American Community Survey. American Community Survey 2014-2018, 5-year Estimates. Available from: https://www.census.gov/library/visualizations/interactive/ 2014-2018-poverty-rate-by-county.html. Accessed December 15, 2020.

20. Zhang X, Holt JB, Lu H, et al. Multilevel regression and post-stratification for small-area estimation population health outcomes: A case study of chronic obstructive pulmonary disease prevalence using the Behavioral Risk Factor Surveillance System. Am J Epidemiol 2014;179:1025-33.

21. Zhang X, Holt JB, Yun S, Lu H, Greenlund KJ, Croft JB. Validation of multilevel regression and poststratification methodology for small area estimation of health indicators from the Behavioral Risk Factor Surveillance System. Am J Epidemiol 2015;182:127-37.

22. Wang Y, Holt JB, Zhang X, et al. Comparison of methods for estimating prevalence of chronic diseases and health behaviors for small geographic areas: Boston validation study. Prev Chronic Dis 2013;14:

23. Ryan L. Spatial epidemiology: some pitfalls and opportunities. Epidemiology 2009;20:242-4.

24. Condon P. Mixture of spatial and unstructured effects for spatially discontinuous health outcomes. Comput Stat Data An 2007;51:-3197-212.

25. United States Census Bureau. Population Division. County Population by Characteristics: 2010-2019. Nation, States and Counties Population. Annual Estimates of The Resident Population by Age, Sex, Race, and Hispanic Origin: April 1, 2010-July 1, 2018. Available from: https://www.census.gov/data/ tables/time-series/demo/popest/2010s-countiesdetail.html. Accessed December 15, 2020.

26. Fedewa SA, Ward EM, Brawley O, Jemal A. Recent patterns of prostate-specific antigen screening for prostate cancer screening in the United States. JAMA Intern Med 2017;177:1040-2.

27. Jemal A, Fedewa SA, Ma J, et al. Prostate cancer incidence and PSA screening patterns in relation to USPSTF screening recommendations. JAMA 2015;314: 2054-61.

28. US Centers for Medicare \& Medicaid. Prostate Cancer Screening. Available from: www.medicare. gov/coverage/prostate-cancer-screenings.html. Published 2020. Accessed: December 2, 2020.

29. Smith RA, Andrews KS, Brooks D, et al. Cancer screening in the United States, 2018: a review of current American Cancer Society guidelines and current issues in cancer screening. CA Cancer J Clin 2018;68:297-316. Available from: https://doi. org/10.3322/caac.21446.

30. Carter HB, Albertsen PC, Barry MJ, et al. Early detection of prostate cancer (2018): American Urological Association (AUA) guideline. Available from: https:/www.auanet.org/guidelines/prostatecancer-early-detection-guideline. Accessed December 10, 2020.

31. Brawley OW. Trends in prostate cancer in the United States. J Natl Cancer Inst Monogr 2012;2012:152-6.

32. Population Reference Bureau. Appalachia's Aging Population. Available from: https://www.prb.org/ 
appalachias-aging-population-more-residents-ages65-fewer-ages-25-to-64-signals-challenges-ahead/. Accessed December 15, 2020.

33. Naylor KB, Tootoo J, Yakusheva O, Shipman SA, Bynum JPW, Davis MA. Geographic variation in spatial accessibility of U.S. healthcare providers. PLoS One 2019;14:e0215016. Available from: http://doi.org/10.1371/journal.pone.0215016.

34. Choi SK, Seel JS, Steck SE, et al. Talking about your prostate: perspectives from providers and community members. J Canc Educ 2018;33:1052-60.

35. Rosenberg M, Crawford D, Newmark J, Steiner M. Use of PSA screening guidelines among primary care physicians (sec mp39-01). J Urol 2016;195:e541.

36. Henley SJ, Ward EM, Scott S, et al. Annual report to the nation on the status of cancer, part I: national cancer statistics. Cancer 2020;126:2225-49.

37. Jemal A, Culp MB, Ma J, Islami F, Fedewa SA. Prostate cancer incidence 5 years after US Preventive Services Task Force recommendations against screening. J Natl Cancer Inst 2020. Preprint.

38. American Cancer Society. Key Statistics for Prostate Cancer. Available from: https://www.cancer.org/ cancer/prostate-cancer/about/key-statistics.html. Accessed December 15, 2020.

39. Centers for Disease Control and Prevention. United States Cancer Statistics: Data Visualiza- tions. Available from: https://gis.cdc.gov/Cancer/ USCS/DataViz.html. Accessed December 15, 2020.

40. Pollack CE, Noronha G, Green GE, Bhavsar NA, Carter HB. Primary care providers' response to the US Preventive Services Task Force draft recommendations on screening for prostate cancer. Arch Intern Med 2012;172:668-70.

41. Squiers LB, Bann CM, Dolina SE, Tzeng J, McCormack L, Kamerow D. Prostate-specific antigen screening: men's responses to 2012 recommendation against screening. Am J Prev Med 2013;45:182-9.

42. DeWitt-Foy ME, Gam K, Modlin C, et al. Race, decisional regret and prostate cancer beliefs: identifying targets to reduce racial disparities in prostate cancer. J Urol 2021;205:426-33.

43. The Social Security Administration. Actuarial life tables. Available from: https://www.ssa.gov/oact/ STATS/table4c6.html. Accessed December 15, 2020.

44. Hidiroglou MA, You Y. Comparison of unit level and area level small area estimators. Surv Methodol 2016;42:41-61.

45. Centers for Disease Control and Prevention. Talk to Nathan. Available from: https://www.cdc.gov/cancer/ prostate/talk-to-nathan/. Accessed December 15, 2020. 
Appendix Table 1. Unweighted and Weighted Percentages of PSA Screening Within One Year by Age and Race and Ethnicity Groups, BRFSS 2018, $(\mathrm{n}=116,654)^{* \dagger}$

\begin{tabular}{lccc}
\hline Age Group, years & Sample Size & Unweighted \% ${ }^{\ddagger}$ & Weighted \% (95\% CI) \\
\hline 40 to 49 & 22,561 & 4.32 & $4.51(4.04-5.03)$ \\
50 to 59 & 29,595 & 16.90 & $16.81(15.98-17.68)$ \\
60 to 69 & 33,718 & 30.79 & $30.30(29.25-31.36)$ \\
70 to 79 & 21,449 & 37.28 & $37.50(35.96-39.05)$ \\
$\geq 80$ & 9,331 & 23.50 & $23.38(21.48-25.39)$ \\
Race and ethnicity & & & $22.26(21.75-22.78)$ \\
NH white & 92,133 & 24.43 & $18.40(17.01-19.87)$ \\
NH black & 8,044 & 21.12 & $12.46(9.42-16.31)$ \\
NH AIAN & 2,009 & 12.10 & $12.26(9.72-15.33)$ \\
NH Asian & 2,076 & 14.45 & $11.48(7.11-18.00)$ \\
NH PI & 369 & 10.57 & $15.02(12.79-19.40)$ \\
NH $\geq 2$ races & 2,024 & 15.12 & $11.65(10.04-13.48)$ \\
Hispanic & 6,572 & 11.41 & \\
\hline
\end{tabular}

BRFSS, Behavioral Risk Factor Surveillance System; PSA, Prostate-Specific Antigen; CI, Confidence interval; NH, Non-Hispanic; AIAN, American Indian Alaska Native; PI, Pacific Islander.

${ }^{*}$ We excluded the $\mathrm{NH}$ other race group in our analysis to match the US Census race and ethnicity categorization, which we used in our simulation models.

${ }^{\dagger}$ Sample size is the number of men who answered the question whether they had had a PSA test in the past year (Yes/No or never).

${ }^{\ddagger}$ An unweighted percentage is the percentage of men reporting having had a PSA screening test within 1 year of the interview in a specific age or race and ethnicity group category. Weighted percentage is an estimate of the prevalence of having had a PSA screening test in the past year in a specific age or race and ethnicity group in the study population. 
Appendix Figure 1. Model-Based Estimated County Prevalence Maps for Men with Prostate-Specific Antigen (PSA) Screening as Part of a Routine Examination Within the Past Year, By Age-Group, Using 2018 Data. Abbreviation: BRFSS, Behavioral Risk Factor Surveillance System.
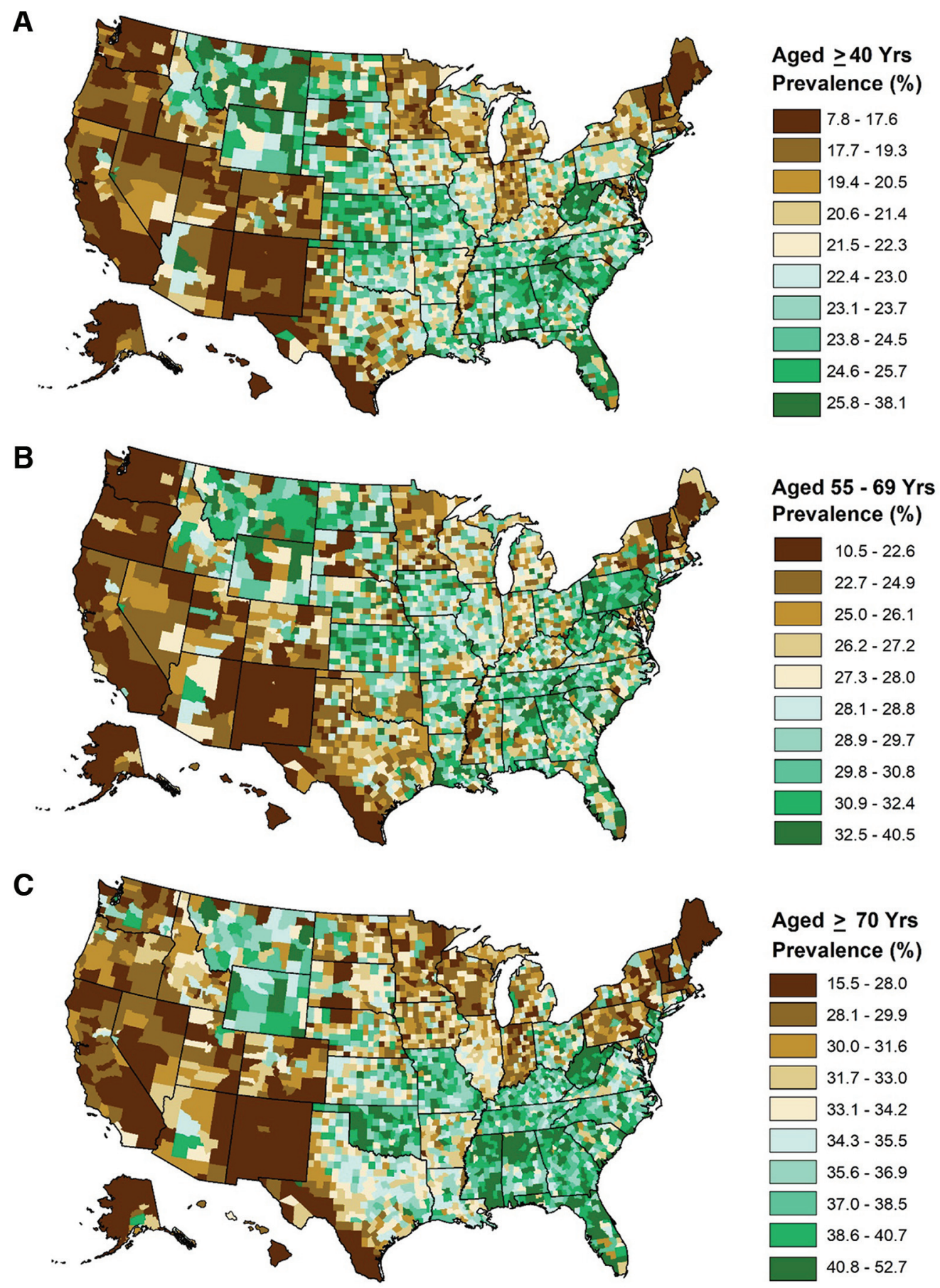

Note: The county prevalence shown on the right of each map describes the prevalence by deciles, with each associated with a different color scale. Prevalence is presented as a percentage (\%). Model-based results are based on data from the 2018 BRFSS, US Census 2018 American Community Survey 5-year county level poverty estimates, and the 2018 US Census estimated county population counts. 